Zhao, S., Stojanovic, A., Angelica, E., Emery, o., Rentsch, D., Pauer, R., ... Malfait, W. J. (2019). Phase transfer agents facilitate the production of superinsulating silica aerogel powders by simultaneous hydrophobization and solvent- and ion-exchange. Chemical Engineering Journa1, 122421. https://doi.org/10.1016/j.cej.2019.122421

This manuscript version is made available under the CC-BY-NC-ND 4.0

license http://creativecommons.org/1icenses/by-nc-nd/4.0/

\title{
Phase transfer agents facilitate the production of superinsulating silica aerogel powders by simultaneous hydrophobization and solvent- and ion-exchange
}

Shanyu Zhao ${ }^{a}$, , Ana Stojanovic ${ }^{a}$,Emanuele Angelica ${ }^{a}$, Olivier Emerya, Daniel Rentsch ${ }^{b}$, Robin Pauerc, Matthias M. Koebel ${ }^{\mathrm{a}}$ and Wim J. Malfait ${ }^{\mathrm{a}, *}$

${ }^{a}$ Laboratory for Building Energy Materials and Components, Empa, Swiss Federal Laboratories for Materials Science and Technology, Überlandstrasse 129, CH-8600 Dübendorf, Switzerland.

${ }^{b}$ Laboratory for Functional Polymers, Empa, Swiss Federal Laboratories for Materials Science and Technology, Überlandstrasse 129, CH-8600 Dübendorf, Switzerlond.

c Electron Microscopy Center, Empa, Swiss Federal Laboratories for Materials Science and Technology, Überlandstrasse 129, CH-8600 Dübendorf, Switzerland.

Abstract: A fast and simple, one-step synthesis for the preparation of silica aerogel powders is reported. A waterglass based sol was prepared without prior ion-exchange and stirred with an immiscible organic phase (heptane) that contains the hydrophobization agent (hexamethyldisilazane). The addition of nitric acid triggers gelation and subsequently the hydrophobization of this hydrogel, which causes the gel particles to transfer from the aqueous into the organic phase, whilst the sodium and nitrate ions are retained in the aqueous phase. The resulting organogel slurry is then converted into a silica aerogel powder by means of ambient pressure drying. The addition of phase transfer agents, ethanol and isopropanol in particular, strongly influences the final silica aerogel properties, including tap density, hydrophobicity, particle size distribution, surface chemistry (solid-state NMR), and microstructure (TEM, SEM, nitrogen 
sorption). The addition of intermediate amounts of phase transfer agent strongly improves the aerogel properties, but these positive effects disappear when larger quantities are added. Under optimal conditions, silica aerogel powders with high mesoporosity, surface areas above $800 \mathrm{~m}^{2} / \mathrm{g}$, tap densities as low as $0.083 \mathrm{~g} / \mathrm{cm}^{3}$, and thermal conductivities below $20 \mathrm{~mW} \mathrm{~m}^{-1} \mathrm{~K}^{-1}$ can be produced in a one-step process within just over two hours. The direct use of waterglass as an inexpensive silica precursor provides a great opportunity to reduce the production cost of silica aerogel powders for thermal insulation applications.

Keywords: silica aerogel; phase transfer agent; solid-state NMR, nitrogen sorption

\section{Corresponding authors:}

Shanyu Zhao, shanyu.zhao@empa.ch, +41 587654244

Wim J. Malfait, wim.malfait@empa.ch, +41 587654983 


\section{Highlights}

- Simple aerogel synthesis from low-cost silica precursor without ion exchange

- Superinsulating silica aerogel powder produced in less than three hours

- Phase transfer agent improves hydrophobization and application relevant properties

- Silica aerogel powder displays high surface area and mesopore volume

\section{Graphical abstract}
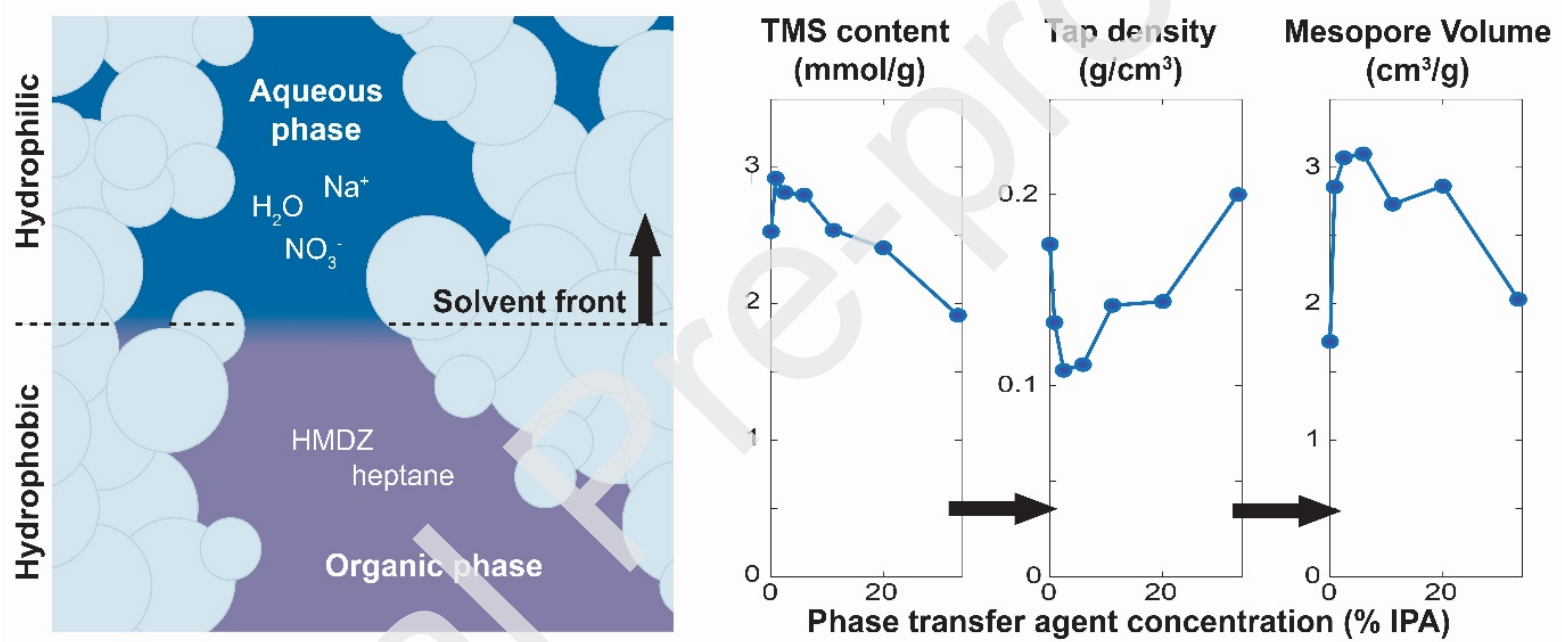


\section{Introduction}

Silica aerogel's record-breaking low thermal conductivity has led to the emergence of a rapidly growing market for silica aerogel based thermal insulation products [1-4]. However, entry into mainstream insulation markets is limited because of two important drawbacks: i) the poor mechanical properties and ii) the high production cost. Improving the mechanical properties of silica aerogel has been and continues to be a topic of intense academic research [5-16], but until now, none of the resulting materials are available in industrial quantities, despite the excellent thermal and mechanical properties. This inability of these strong aerogels to reach the market highlights the importance of cost as the major barrier for market entry for reinforced aerogels and for market growth for regular silica aerogel.

Industrially, both supercritical drying with $\mathrm{CO}_{2}(\mathrm{SCD})$ and evaporative, ambient pressure drying (APD) are employed for silica aerogel production, where the former is most common for aerogel blankets and the latter is more common for particulate aerogel, i.e. granulate or powders. Regardless of the selected drying technique, a hydrophobization treatment is almost always carried out on the material to ensure a good stability against liquid water and water vapour, which is relevant in most practical applications. In the case of APD, however, the hydrophobization is also a key processing requirement. Without hydrophobization, the gels shrink under the strong capillary forces that occur at the gas-liquid interfaces within the mesopores and this densification is irreversible owing to condensation reactions between surface silanol groups, 2 इSi-OH $\leftrightarrow \equiv \mathrm{Si}-\mathrm{O}-\mathrm{Si} \equiv+\mathrm{H}_{2} \mathrm{O}$. A hydrophobization treatment prior to APD circumvents this reaction and enables the gels to recover most of the original gel volume through the spring-back effect [17], provided that the gels have been aged sufficiently to strengthen the silica particle network [18].

The most common hydrophobization strategy is to substitute surface silanol groups with trimethylsilyl groups (TMS) through the use of trimethylchlorosilane (TMCS) [19-21], trimethylethoxysilane (TMES) [22], hexamethyldisilazane (HMDZ) [23-25] or hexamethyldisiloxane (HMDSO) [26, 27], usually through a post-gelation surface modification. All of these 
hydrophobization agents have specific advantages and disadvantages: TMCS and HMDZ display a high reactivity, but generate stoichiometric amounts of $\mathrm{HCl}$ and ammonia, respectively; HMDSO does not release any toxic or corrosive by-products, but is only moderately reactive and requires the use of an acid catalyst. As an alternative to TMS modification, inherently hydrophobic aerogels that contain monomethylsilyl and dimethylsilyl groups can be synthesized, for example by using methyltri(m)ethoxysilane (MTMS/MTES) and/or dimethyldi(m)ethoxysilane (DMDMS/DMDES) precursors [28-31], or these reagents can be used during a post-gelation hydrophobization treatment [32], but hydrophobization with TMS protecting groups remains the most common approach.

The standard, academic method for hydrophobization with TMS groups involves the exchange of the gelation solvent, typically water for waterglass or ethanol for alkoxide precursors, with a modification solution that contains the hydrophobization agent (e.g. TiVICS, HMDZ, HMDSO), an organic solvent (e.g. heptane, ethanol) and an optional catalyst (e.g. $\mathrm{HCl}$ for hydrophobization with $\mathrm{HMDSO}$ ). If the gelation and modification solvent are not miscible, an intermediate solvent exchange is required, i.e. a first exchange from water to ethanol followed by a second exchange from ethanol to heptane. An important feature of this approach is that during the entire process, only a single, mixed solvent phase is present. This enables a precise control of the process parameters, but the procedure is lengthy and consumes large quantities of solvent since the solvent exchanges proceed through diffusive equilibration and dilution of the initial pore fluid in the exchange solvent. Recently, we have developed a fast and minimal-solvent process for the production of hydrophobic silica aerogel where the hydrophobization agent (HMDSO) was included into the sol prior to gelation and activated by the addition of an acid catalyst after gelation [26, 33], avoiding the need for diffusive equilibration of hydrophobe concentrations.

In contrast to the single-phase diffusive equilibration/dilution approach described above, one can take advantage of the immiscibility between water and non-polar organic solvents to carry out a simultaneous hydrophobization - solvent/ion exchange step [19, 34-40]. Here, the solvent exchange process does not proceed through a single-phase diffusive equilibration between miscible solvents, 
but the silica surfaces in the hydrogel are progressively silylated as the interface between the aqueous phase and the organic solvent (that carries the hydrophobe) moves through the hydrogel and displaces the pore water with the non-polar solvent. This approach is attractive for large scale production as it enables accelerated processing and potentially reduces solvent consumption. In addition, because ions will partition preferentially into the aqueous phase, and the hydrophobic gel moves into the organic phase, this process can be carried out without any ion-exchange step prior to gelation. More recent variations of this approach to the synthesis of powders [27, 41-45] include gelation, hydrophobization, and solvent and ion-exchange in one single step. Hydrophobic silica aerogel powders are produced through the addition of an acid to a vigorously stirred two-phase mixture of waterglass and an organic phase (e.g. heptane-HMDZ). The acid addition triggers the gelation of the waterglass and, simultaneously, the hydrophobization and phase transfer from the gel into the organic phase. This process is straightforward and potentially cost-effective, but because the processing steps are not separated in time anc' space, the overall progression of the process is hard to control and the resulting material quality can be difficult to predict and maintain.

We have recently compared the fast synthesis of silica aerogel powders from the three most common precursors, tetraethoxysilane (TEOS), ion-exchanged waterglass, and regular (non-ionexchanged) waterglass [46]. Here, we focus on aerogel powders produced from the least expensive precursor, waterglass without ion-exchange, and systematically investigate the role of adding a phase transfer agent (PTA) to facilitate the phase transfer from the gel from the aqueous gelation solvent into the organic phase. The amounts of ethanol and isopropanol PTAs were varied over a wide range of concentrations and the resulting aerogel quality followed by BET and solid-state NMR spectroscopy. Material quality was found to increase upon the initial addition of PTA, but decrease at higher PTA loadings.

\section{Experimental section}




\subsection{Materials and reagents}

Sodium silicate solution $\left(26.5 \% \mathrm{w} / \mathrm{w} \mathrm{SiO}_{2}, \mathrm{Na}_{2} \mathrm{O}: \mathrm{SiO}_{2}\right.$ molar ratio=1:3.1) was purchased from SigmaAldrich. Hexamethyldisilazane (98.5\%, ABCR chemicals, Germany) was used as hydrophobization agent. Heptane (UN 1206, Brenntag Schweizerhalle AG) and deionized water were used as solvents. Ethanol (F25-AF-MEK ethanol denatured with 2\% methyl ethyl ketone, Alcosuisse, Switzerland) and isopropanol (99\%, Thommen-Furler) were used as PTA. Nitric acid $\left(\mathrm{HNO}_{3}, 70 \%\right.$ in water) was purchased from Sigma-Aldrich, Switzerland. All chemicals were used as received without purification.

\subsection{One-step synthesis of aerogel powder}

The synthesis procedure is summarized in Figure $1.50 \mathrm{ml}$ of diluted water glass (WG) with a concentration of $4.5 \mathrm{wt} . \%$ of $\mathrm{SiO}_{2}$ is used as the silica precursor. Under constant stirring at $400-800$ $\mathrm{rpm}$ at $65^{\circ} \mathrm{C}, 60 \mathrm{ml}$ of heptane is added, followed by the addition of $6 \mathrm{ml}$ of HMDZ. The gelation was triggered by adding $4 \mathrm{ml}$ of concentrated nitric acid (70\%) to the stirred two-phase mixture. After 30 minutes stirring, a variable amount of either of two selected PTAs (isopropanol (IPA) or ethanol) is added. Because the PTA is added 30 minutes after the addition of the acid gelation catalyst, the dilution of the aqueous sol with PTA, the subsequent reduction of the silica content of the sol, or major effects on the gel structure formation are not to be expected. The type and amount of PTA are the only parameters that are varied in this study (Table 1 ). The addition of acid initiates the gelation of the waterglass, the hydrophobization of the gel surfaces, the displacement of the aqueous phase from the gel, and the phase transfer of the gel into the organic phase. The sodium and nitrate ions are retained in the aqueous phase and the phase transfer thus constitutes a simultaneous ion and solvent exchange. Typically, the entire process of gelation, hydrophobization and phase transfer is completed between 50 minutes and 1 hour. For all reported experiments, the stirring is stopped after 1 hour and the aqueous phase, with the sodium and nitrate ions, is decanted. The slurry that 
contains the hydrophobized organogel particles in the organic phase is dried at ambient pressure for $1 \mathrm{~h}$ at $150^{\circ} \mathrm{C}$.

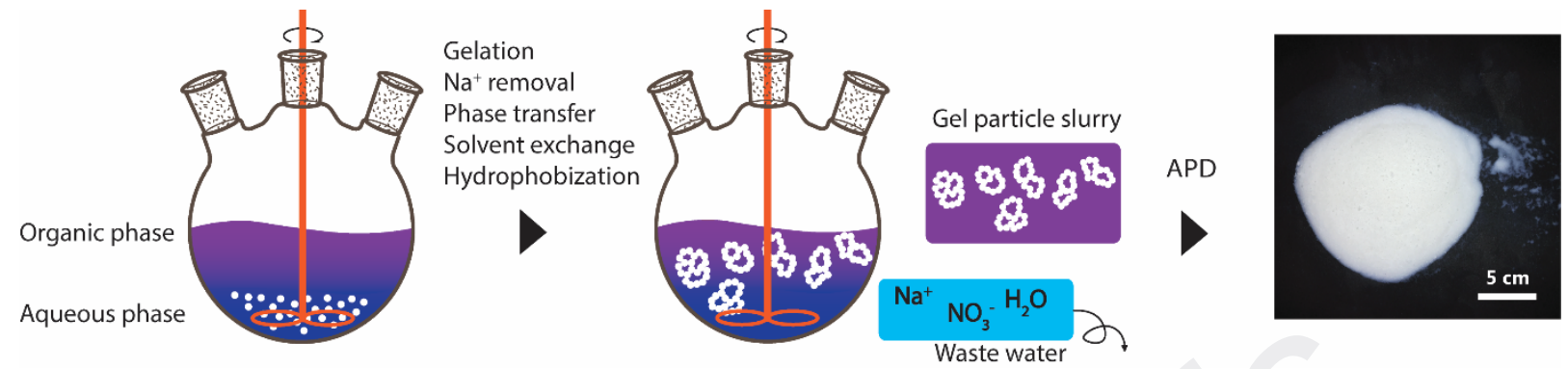

Figure 1. Schematic illustration of the silica aerogel powder production process.

Table 1. Overview of experimental parameters.

\begin{tabular}{|c|c|c|c|c|c|c|c|c|c|c|c|}
\hline \multirow{3}{*}{$\begin{array}{c}\text { Sample } \\
\text { label }\end{array}$} & \multirow{3}{*}{$\begin{array}{l}\text { WG } \\
{[\mathrm{ml}]}\end{array}$} & \multirow{3}{*}{$\begin{array}{l}\mathrm{H}_{2} \mathrm{O} \\
{[\mathrm{ml}]}\end{array}$} & \multirow{3}{*}{$\begin{array}{c}\text { HMDZ } \\
\text { [ml] }\end{array}$} & \multirow{3}{*}{$\begin{array}{c}\text { Heptane } \\
\text { [ml] }\end{array}$} & \multirow{3}{*}{$\begin{array}{c}\mathrm{HNO}_{3} \\
{[\mathrm{ml}]}\end{array}$} & \multicolumn{4}{|c|}{ Phase transfer agent } & \multicolumn{2}{|c|}{ Drying } \\
\hline & & & & & & \multirow[b]{2}{*}[\mathrm{ml}]{} & \multirow{2}{*}[\mathrm{v}\%]{$^{*}$} & \multicolumn{2}{|c|}{$\mathrm{EtOH}$} & \multirow{2}{*}{$\begin{array}{c}\mathrm{T} \\
{\left[{ }^{\circ} \mathrm{C}\right]}\end{array}$} & \multirow{2}{*}{$\begin{array}{l}\mathrm{t} \\
{[\mathrm{h}]}\end{array}$} \\
\hline & & & & & & & & {$[\mathrm{ml}]$} & {$[\mathrm{v} \%]^{*}$} & & \\
\hline i0 & 8.5 & 41.5 & 6 & 60 & 4 & 0 & 0.0 & - & - & 150 & 1 \\
\hline ¡1 & 8.5 & 41.5 & 6 & 60 & 4 & 1 & 0.8 & - & - & 150 & 1 \\
\hline i3 & 8.5 & 41.5 & 6 & 60 & 4 & 3 & 2.4 & - & - & 150 & 1 \\
\hline $\mathrm{i} 7.5$ & 8.5 & 41.5 & 6 & 60 & 4 & 7.5 & 5.9 & - & - & 150 & 1 \\
\hline ¡15 & 8.5 & 41.5 & 6 & 60 & 4 & 15 & 11.1 & - & - & 150 & 1 \\
\hline ¡30 & 8.5 & 41.5 & 6 & 60 & 4 & 30 & 20.0 & - & - & 150 & 1 \\
\hline$i 60$ & 8.5 & 41.5 & 6 & 60 & 4 & 60 & 33.3 & - & - & 150 & 1 \\
\hline e1 & 8.5 & 41.5 & 6 & 60 & 4 & - & - & 1 & 0.8 & 150 & 1 \\
\hline e3 & 8.5 & 41.5 & 6 & 60 & 4 & - & - & 3 & 2.4 & 150 & 1 \\
\hline e15 & 8.5 & 41.5 & 6 & 60 & 4 & - & - & 15 & 11.1 & 150 & 1 \\
\hline e30 & 8.5 & 41.5 & 6 & 60 & 4 & - & - & 30 & 20.0 & 150 & 1 \\
\hline
\end{tabular}

* expressed as volume percent of the total amount of reagents used 


\subsection{Characterization}

Scanning Electron Microscopy (SEM) images were recorded with a FEI Nova NanoSEM 230 (FEl, Hillsboro, Oregon, USA) at an accelerating voltage of $10 \mathrm{kV}$ and a working distance around $5 \mathrm{~mm}$. Samples were coated with Pt prior to SEM analysis to avoid charging. The Pt thickness, as measured on the flat surface of the quartz piezoelectric detector of the coater is $20 \mathrm{~nm}$, but the effective thickness on the high surface area aerogels will be much lower.

For TEM analysis, aerogel powder samples were ground and dispersed in methanol. After ultrasonic dispersion, the solution was dropped onto a lacey Cu TEM grid (S166-2, Plano GmbH, Germany), and the grid loaded on a single tilt sample holder. High resolution transmission electron microscopy (HRTEM) images were recorded on a JEM-2200FS field emission electron microscope (JEOL, Japan) with an accelerating voltage of $200 \mathrm{kV}$.

Solid-state (SS) magic angle spinning (MAS) nuclear magnetic resonance (NMR) spectra were acquired on a Bruker Avance III spectrometer equipped with a 9.4 T magnet, corresponding to ${ }^{1} \mathrm{H},{ }^{13} \mathrm{C}$ and ${ }^{29} \mathrm{Si}$ Larmor frequencies of $4.00 .2,100.6$ and $79.5 \mathrm{MHz}$, respectively. All chemical shifts are externally referenced to tetramethy. silane at $0.0 \mathrm{ppm}$ with a precision of $0.1 \mathrm{ppm}$. Quantitative, single pulse ${ }^{1} \mathrm{H}$ NMR spectra were acquired using a $2.5 \mathrm{~mm}$ CP-MAS probe, zirconia rotors, a MAS rate of $24 \mathrm{kHz}, 32$ scans, and a recycle delay of $15 \mathrm{~s}$, well in excess of 5 times $T 1$ (typically between 1 and 2 seconds). The spectrum acquired from an empty rotor was subtracted to remove background signals from the rotor and the probe. Quantitative compositional data were extracted from the spectra using an external calibration with reference compounds and a simple integration of the peak intensities with an estimated relative uncertainty on the TMS concentration of $10 \%[47,48] .{ }^{1} \mathrm{H}-{ }^{13} \mathrm{C}$ and ${ }^{1} \mathrm{H}^{29} \mathrm{Si}$ cross polarization (CP) MAS NMR spectra were acquired with a $7.5 \mu \mathrm{s} 90^{\circ}$ excitation pulse on the ${ }^{1} \mathrm{H}$ channel, contact times of $5 \mathrm{~ms}$ and $2 \mathrm{~ms}$, respectively, with a ramp from 100 to $50 \%$ of power level on the ${ }^{1} \mathrm{H}$ channel (ramp from 33 to $23 \mathrm{kHz}$ ), $33 \mathrm{kHz}$ SPINAL 64 proton decoupling during acquisition, zirconia rotors, a MAS rate of $4 \mathrm{kHz}$, between 200 and 500 scans, and a recycle delay of 2 $\mathrm{s}$ on a $7 \mathrm{~mm}$ CP-MAS probe. 
Nitrogen sorption analysis was carried out on an TriFlex nitrogen sorption analyzer (Micromeritics, US) following prior degassing for 20 hours at $250^{\circ} \mathrm{C}$ and 0.02 mbar. The specific surface areas $\left(\mathrm{S}_{\mathrm{BET}}\right.$, uncertainty $\left.\sim 20 \mathrm{~m}^{2} / \mathrm{g}\right)$ were obtained using BET [49] and the pore volume $\left(\mathrm{V}_{\mathrm{BJH}}\right)$ and average pore size $\left(D_{\text {вJH }}\right)$ using BJH analysis [50], where the latter two are regarded as qualitative only due to the known limitations of nitrogen sorption analysis to determine the pore volume and size distribution of silica aerogel [51].

The tap density was calculated from the respective mass and volume of the aerogel powders using a Jolting Volumeter type STAV II (J. Engelsman, Germany) with a measurement cylinder of $10 \mathrm{~cm}^{3}$ after 100 taps and an estimated relative uncertainty of $2 \%$.

The particle size distribution (PSD) was measured by distributing the aerogel powders in isopropanol in a Beckmann Coulter LS 13320 particle size analyser with an obscuration value between 7 and 12\%.

The thermal conductivity was measured using a custom-built guarded hot plate device (guarded zone: $50 \mathrm{~mm} \times 50 \mathrm{~mm}$, measuring zone: $25 \mathrm{~mm} \times 25 \mathrm{~mm}$, cold plate $15^{\circ} \mathrm{C}$, hot plate $30^{\circ} \mathrm{C}$ ) designed for small specimens of low thermal conductivity materials [52]. Because materials are only available as powders, the thermal conductivity of the aerogel phase itself cannot be determined. As an alternative, the thermal conductivity was measured on a powder bed, i.e. on a mixture of aerogel grains with interstitial air. The powder was packed in an expanded polystyrene frame to keep it in place for the anaiysis. The inner dimensions of the frame $(70 \mathrm{~mm} \times 55 \mathrm{~mm}$ ) were larger than the guarded zone to ensure that the frame did not affect the measurements. Two samples were analysed. The density of the powder bed during the analysis of a larger batch of the 115 sample was $0.105 \mathrm{~g} / \mathrm{cm}^{3}$ (Table S1). A commercial silica aerogel powder (Cabot IC3100) was measured using the same procedure with a density of the powder bed of $0.098 \mathrm{~g} / \mathrm{cm}^{3}$. The measurements were repeated three times for both samples and the precision/reproducibility was better than $0.5 \mathrm{~mW} /(\mathrm{m} \cdot \mathrm{K})$, but the accuracy is estimated to be about $1 \mathrm{~mW} /(\mathrm{m} \cdot \mathrm{K})$. 
Water contact angle measurements require a flat surface and thus cannot be performed directly on the silica aerogel powders. We therefore measured the water contact angle on the top surface of compressed powder pellets. Note that this approach strongly modifies the surface roughness and the reported contact angles provide only a qualitative reflection of the aerogel's hydrophobicity. The surface wettability of aerogels was evaluated by contact angle measurement using a Contact Angle System OCA (Dataphysics TBU 90E, Germany), combined with a high-speed camera. The volume of the water droplet was $5 \mu \mathrm{L}$, and the tip used was a precision stainless steel tip (Gauge 32, EFD). The uncertainty on the water contact angle is estimated at approximately $5^{\circ}$, but the effects of the compression prior to the measurement may be much larger.

\section{Results}

\subsection{Surface chemistry}

Here, we evaluate the effect of the addition of PTAs, and isopropanol in particular, on the surface chemistry of the silica aerogel powders.

Solid-state NMR spectra of the silica powders prepared with variable amounts of isopropanol added as PTA display the same main resonances, with relatively small, but systematic variations in relative peak intensities (Figure 2). Before discussing these variations in detail, it is important to discuss the limitations of solid-state NMR for quantification purposes. The ${ }^{1} \mathrm{H}$ NMR spectra are fully quantitative because they were acquired on carefully weighed samples, using the same filling factor of the rotors, and with sufficiently long recycle delays in between pulses (>5.T1), and the intensities have been calibrated against reference compounds $[47,48]$. In contrast, the peak intensities in the ${ }^{1} \mathrm{H}-{ }^{13} \mathrm{C}$ and ${ }^{1} \mathrm{H}-29 \mathrm{Si}$ CP MAS NMR spectra are not a quantitative representation of the species concentrations, but are modified by different polarization transfer efficiencies and different relaxation times. However, because the spectra were acquired under identical conditions, and because of the overall similarity in 
terms of composition and speciation, relative changes of peak ratios between different samples do provide a qualitative estimate of changes in surface chemistry.

The ${ }^{1}{ }^{\mathrm{H}-}{ }^{29} \mathrm{Si} \mathrm{CP}$ MAS NMR spectra display the typical resonances expected for hydrophobic silica aerogels (Figure 2a). The signal at $15 \mathrm{ppm}$ is assigned to trimethylsilyl groups grafted on the silica surface $[47,48]$. The $\mathrm{Q}^{\mathrm{n}}$ bands are related to $\mathrm{Si}$ atoms coordinated by $\mathrm{n}$ bridging oxygen atoms and 4$\mathrm{n}$ non-bridging oxygen atoms derived from the waterglass solution, where a bridging oxygen atom

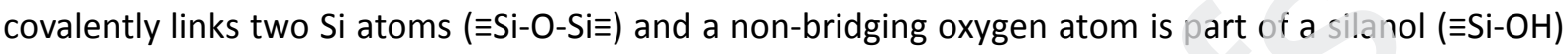
or isopropoxy group $\left(\equiv \mathrm{Si}-\mathrm{O}-(\mathrm{CH})\left(\mathrm{CH}_{3}\right)_{2}\right)[47,48]$. Cross polarization more effectively enhances the signal of depolymerized species $\left(Q^{3}, Q^{2}\right)$ compared to that of $Q^{4}$, leading to exaggerated spectral intensities for $\mathrm{Q}^{3}$ and $\mathrm{Q}^{2}$. The sample prepared without PTA $(0 \mathrm{ml}$ IPA) displays a relatively intense signal for $Q^{3}$ and a clearly visible shoulder for $Q^{2}$. With the addition of even a minor amount of PTA (1 $\mathrm{ml}$ IPA), the relative intensity of the TMS peak increases, the $Q^{2}$ shoulder disappears and the relative intensity of $Q^{3}$ decreases (Figures $2 a, 3 d$ ). The addition of higher amounts of PTA decreases the intensity of the TMS peak and increases the relative intensity of the $\mathrm{Q}^{3}$ peak. At the highest concentrations of PTA, a clear $\mathrm{Q}^{2}$ shoulder reappears in the spectrum (Figure 2a). Thus, the ${ }^{1} \mathrm{H}-{ }^{29} \mathrm{Si} C \mathrm{CP}$ MAS NMR data are indicative of a distinct increase of the silylation efficiency upon the addition of minor amounts of isopropanol, according to reactions of the form:

$$
\mathrm{Q}^{\mathrm{n}}-\mathrm{OH}+\mathrm{Q}^{\mathrm{m}}-\mathrm{OH}+\left(\mathrm{CH}_{3}\right)_{3} \mathrm{Si}-\mathrm{NH}-\mathrm{Si}\left(\mathrm{CH}_{3}\right)_{3} \rightarrow \mathrm{Q}^{\mathrm{n}+1}-\mathrm{Si}\left(\mathrm{CH}_{3}\right)_{3}+\mathrm{Q}^{\mathrm{m}+1}-\mathrm{Si}\left(\mathrm{CH}_{3}\right)_{3}+\mathrm{NH}_{3} \text { with } \mathrm{m}, \mathrm{n}=2 \text { or } 3
$$

followed by a plateau and then a steady decline in hydrophobization efficiency when higher amounts of isopropanol are added (Figure 3b). 
a) ${ }^{1} \mathrm{H}_{-}{ }^{29} \mathrm{Si}$ CP MAS NMR

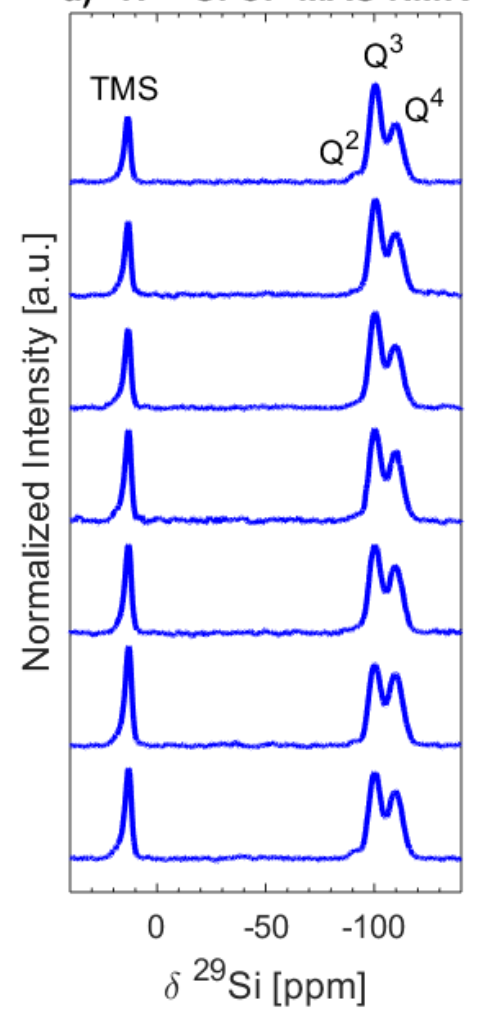

b) ${ }^{1} \mathrm{H}-{ }^{13} \mathrm{C}$ CP MAS NMR

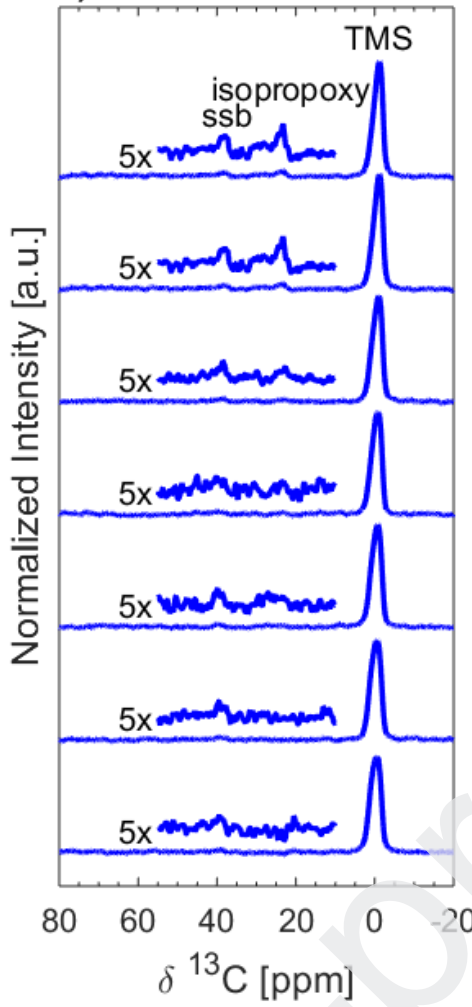

c) Quantitative ${ }^{1} \mathrm{H}$ MAS NMR

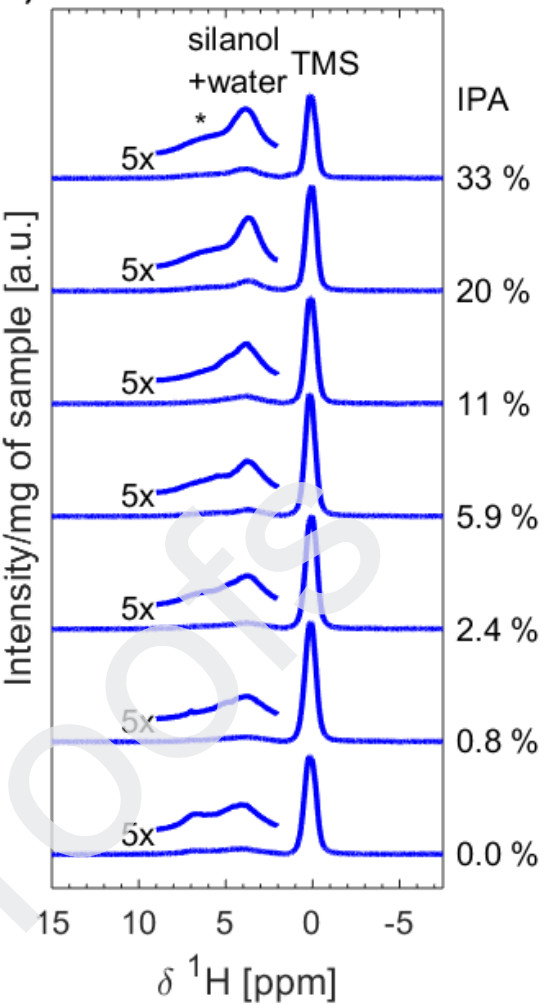

Figure 2. Solid-state MAS NMR spectra of silica aerogel powders prepared with increasing amounts of isopropanol (from bottom to top). a) ${ }^{1} \mathrm{H}^{29} \mathrm{Si}$ CP MAS NMR spectra, normalized to the same total area of the $\mathrm{Q}^{\text {n }}$ resonances. b) ${ }^{1} \mathrm{H}_{-}{ }^{13} \mathrm{C} C \mathrm{CP}$ MAS NMR spectra, normalized to the same total spectral area. c) Quantitative ${ }^{1} \mathrm{H}$ MAS NMR spectra, normalized to the same sample weight and same number of scans. The spectra are offset vertically and the assignment of the resonances is indicated on the figure. The ssb label denotes a spinning sideband and the ${ }^{*}$ an artefact from the incomplete background removal. Certain areas of interest are expanded to visualize the relative changes in intensity of weak resonances.

The ${ }^{1} \mathrm{H}^{-13} \mathrm{C}$ CP MAS NMR spectra display the main resonance from the methyl groups in TMS around 0 $\mathrm{ppm}$, in addition to a weak spinning sideband at $40 \mathrm{ppm}$ (Figure $2 \mathrm{~b}$ ). The powders produced with the highest concentrations of PTA ( $>15 \mathrm{ml}$ IPA) display a weak signal at $24 \mathrm{ppm}$, assigned to isopropyl methyl groups. Presumably, these are isopropoxy groups that are attached to the silica surfaces during alcoholysis reactions of the form:

$$
\equiv \mathrm{Si}-\mathrm{OH}+\mathrm{HO}-(\mathrm{CH})\left(\mathrm{CH}_{3}\right)_{2} \leftrightarrow \equiv \mathrm{Si}-\mathrm{O}(\mathrm{CH})\left(\mathrm{CH}_{3}\right)_{3}+\mathrm{H}_{2} \mathrm{O}
$$


Similar reactions have previously been observed for waterglass based hydrogels that were exchanged into ethanol [48].

Finally, the quantitative ${ }^{1} \mathrm{H}$ MAS NMR spectra display a main resonance around $0 \mathrm{ppm}$ related to the trimethylsilyl groups (Figure 2c). A second broad resonance around $4 \mathrm{ppm}$ can be assigned to silanol and possibly adsorbed water. Although these single pulse ${ }^{1} \mathrm{H}$ NMR spectra were recorded quantitatively (see above), the peak area of the silanol/ $\mathrm{H}_{2} \mathrm{O}$ resonance is hard to quantify because it overlaps with a broad artefact from the incomplete subtraction of the hardware background (around $7 \mathrm{ppm}$ ). The absolute TMS content first increases slightly, reaches a plateau and then decreases with increasing amount of PTA (Table S1, Figure 3a), confirming the qualitative observations from the ${ }^{1} \mathrm{H}$ ${ }^{29} \mathrm{Si}$ CP MAS NMR data (Figure 3b). The relative intensity of the silanol/ $/ \mathrm{H}_{2} \mathrm{O}$ resonance displays an initial decrease followed by an increase at higher IPA contents (Figure 3c). The ${ }^{1} \mathrm{H}-{ }^{29} \mathrm{Si}$ CP MAS NMR data on the $\mathrm{Q}^{3}$ content displays a similar trend (Figure $3 \mathrm{~d}$ ) to that of the silanol/ $\mathrm{H}_{2} \mathrm{O}$ content, consistent with reaction (1).

In summary, the solid-state MAS NMR data indicate that the addition of small amounts of PTA increases the TMS content, i.e. the degree of silylation, through reaction (1), leading to an initial increase of TMS content and a decrease in $\mathrm{Q}^{3}$ and silanol content. For large quantities of PTA, the hydrophobization efficiency declines again, leading to a decrease in TMS content and an increase of $\mathrm{Q}^{3}$ and silanol groups. As will be discussed below, this change in surface chemistry has a profound effect on the final aerogel properties. 

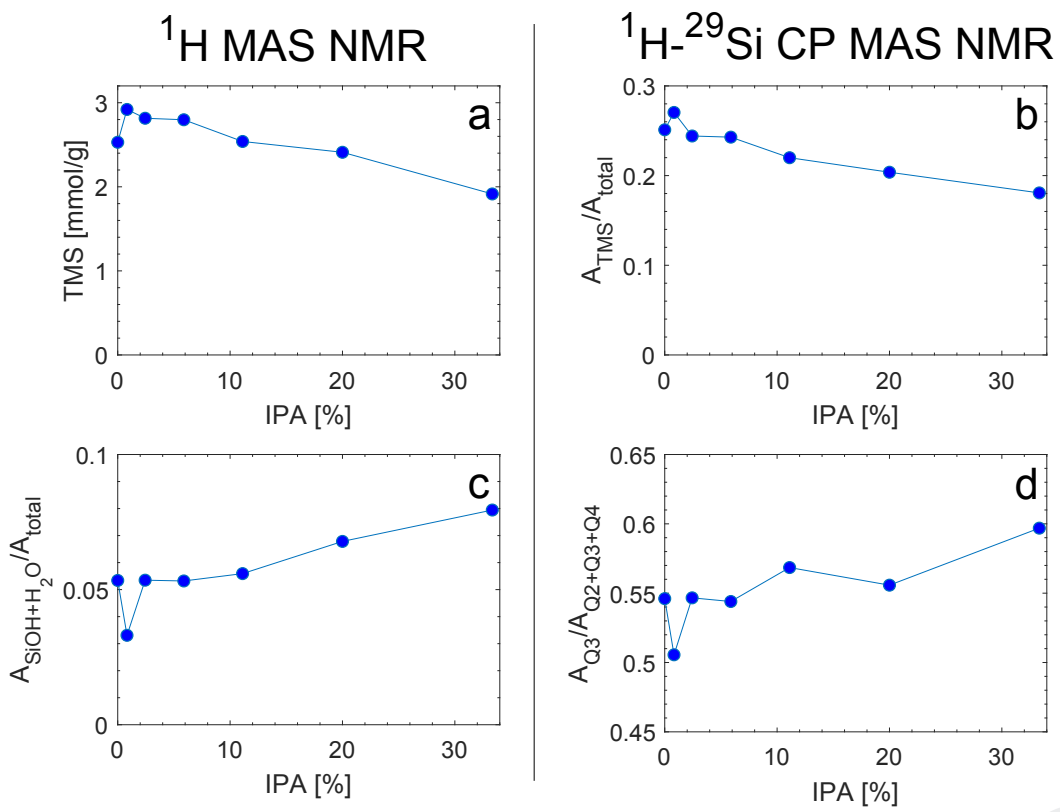

Figure 3. Variation of NMR derived parameters versus amount of PTA added a) TMS content derived from quantitative ${ }^{1} \mathrm{H}$ MAS NMR. b) TMS peak area from ${ }^{1}{ }^{H}-{ }^{29}$ Si CP MAS NiMR. c) Silanol peak area from ${ }^{1} \mathrm{H}$ MAS NMR. d) $\mathrm{Q}^{3}$ peak area from ${ }^{1} \mathrm{H}^{29} \mathrm{Si}$ MAS NMR.

\subsection{Properties and microstructure}

The effects of PTA on the degree of hydrophobization (Figure 3 ) leads to strong variations in the water contact angle, with a clear maximum at intermediate contents of PTA (Figure 4), consistent with the surface chemistry. The cause for the unexpectedly low water contact angles for samples prepared with isopropanol as PTA, in contrast to the samples prepared with ethanol and despite the high degree of silylation of up to $3 \mathrm{mmol} / \mathrm{g}$ TMS, is not known at this point. Please note that these water contact angle measurements had to be conducted on compressed powder pellets, which strongly affects porosity and surface roughness, and the water contact angle values thus do not represent those of the as-prepared aerogels and the results should not be over-interpreted. Measurements on powders directly, i.e. without this compression step, can only be interpreted 
qualitatively (Figure S1). The hydrophobicity of the aerogel powders prepared without PTA and with isopropanol at intermediate loadings, but not for the highest isopropanol content, is typical for hydrophobic silica aerogel powder: aerogel particles coat a near-spherical water droplet with a resulting high contact angle (Figure S1). All prepared powders display broad particle size distributions (Figure S2) with a median particle size between 70 and $160 \mu \mathrm{m}$. For intermediate PTA loadings, the median particle size is the smallest and the width of the distribution narrowest. The goal of this study is not to produce powder with a narrow particle size distribution, but to produce a rogels with a high mesopore volume, high surface area and low thermal conductivity. With respect to thermal conductivity, a broader particle size distribution is actually beneficial as it increases the filling factor (see below).
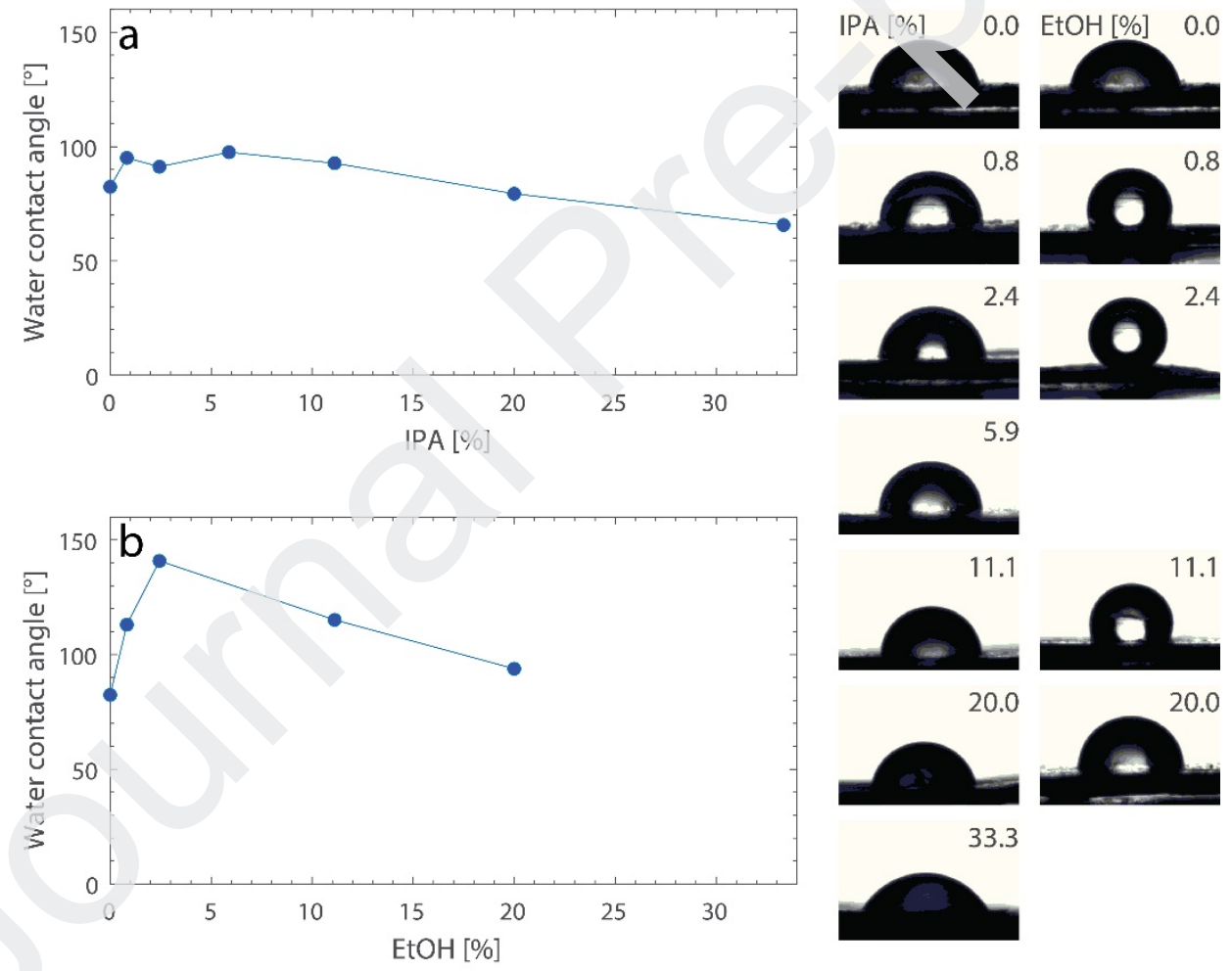

Figure 4. Water contact angles of compressed silica aerogel powder pellets as a function of the amount of PTA added during aerogel powder preparation. 
The addition of the PTA also has a strong effect on the tap densities of the silica aerogel powders (Table S1, Figure 4). Note that the envelope density of the aerogel phase itself cannot be determined directly from the tap density data because the packing efficiency is not known, but is most likely on the order of $25-80 \%$ higher than the tap density, corresponding to a packing efficiency between 80 and 55\%, respectively. The addition of even low amounts of PTA decreases the aerogel tap density from 0.174 to 0.108 and $0.083 \mathrm{~cm}^{3} / \mathrm{g}$ for the addition of $2.4 \%$ of isopropanol and ethanol, respectively. The addition of higher quantities of PTA does not lead to a further decrease in tap density, but rather to an increase. At the optimum amount of PTA ( $3 \mathrm{ml})$, the tap density is lower for the ethanol system, compared to the isopropanol system.
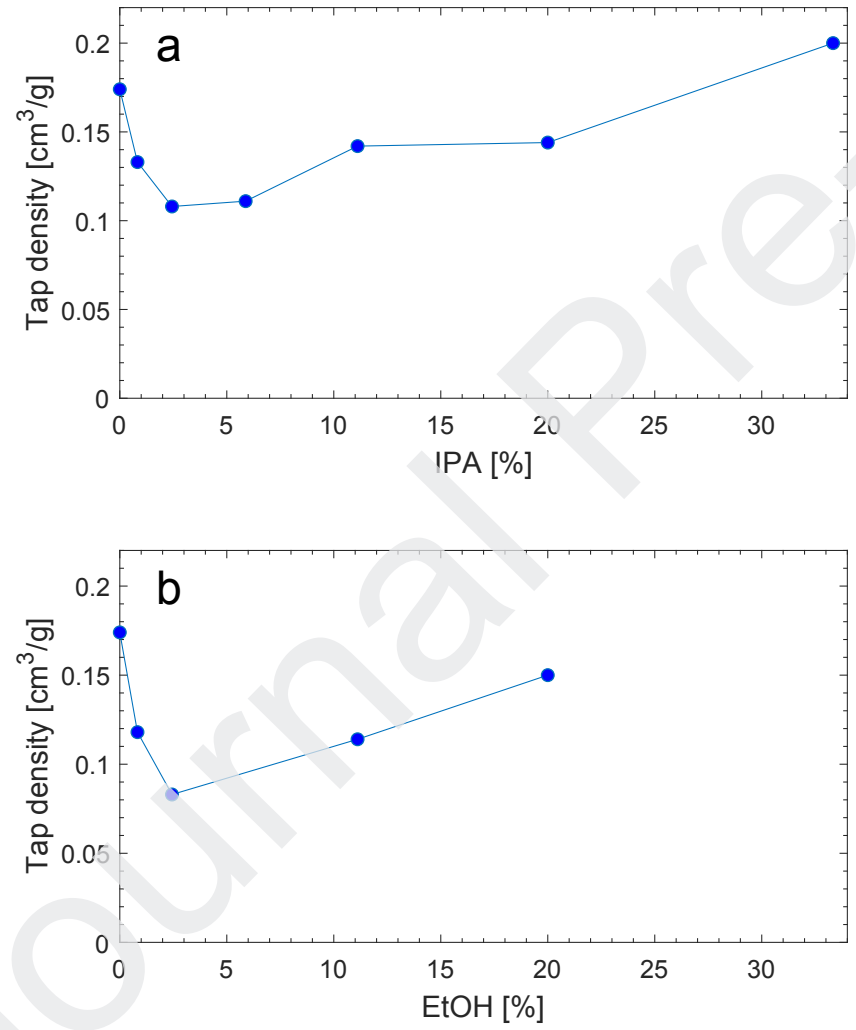

Figure 4. Tap density of the silica aerogel powders versus the amount of PTA added.

All samples display a microstructure that is typical for silica aerogels, with mesopores surrounded by secondary silica particles visible in the SEM images (Figure 5) and a pearl-necklace structure of 
connected primary silica nanoparticles, as observed by TEM (Figure 6). No obvious differences are observed between samples prepared without PTA, with intermediate PTA or with high PTA contents (Figure 6). Because the samples are in powder form, SEM images are collected mostly on external surfaces of the individual grains, which do not fully represent the aerogels' internal structure. In fact, these external surfaces often appear denser than fresh fracture surfaces. In addition, the powders require a relatively thick Pt coating to prevent charging and enable high magnification imaging, and this coating blankets some of the finer structural features, particularly at high magnification, leading to higher apparent densities. Nevertheless, the higher density for the aerogels produced with the lowest and highest contents of PTA is apparent from the SEM images (Figure 5). For example, the sample prepared with $11.1 \%$ of isopropanol (tap density $0.142 \mathrm{~cm}^{3} / \mathrm{g}$ ) displays a higher apparent porosity and larger pore sizes compared to those prepared without isopropanol (tap density 0.174 $\mathrm{cm}^{3} / \mathrm{g}$ ) and with $33.3 \%$ isopropanol (tap density $0.200 \mathrm{~cm}^{3} / \mathrm{g}$ ).
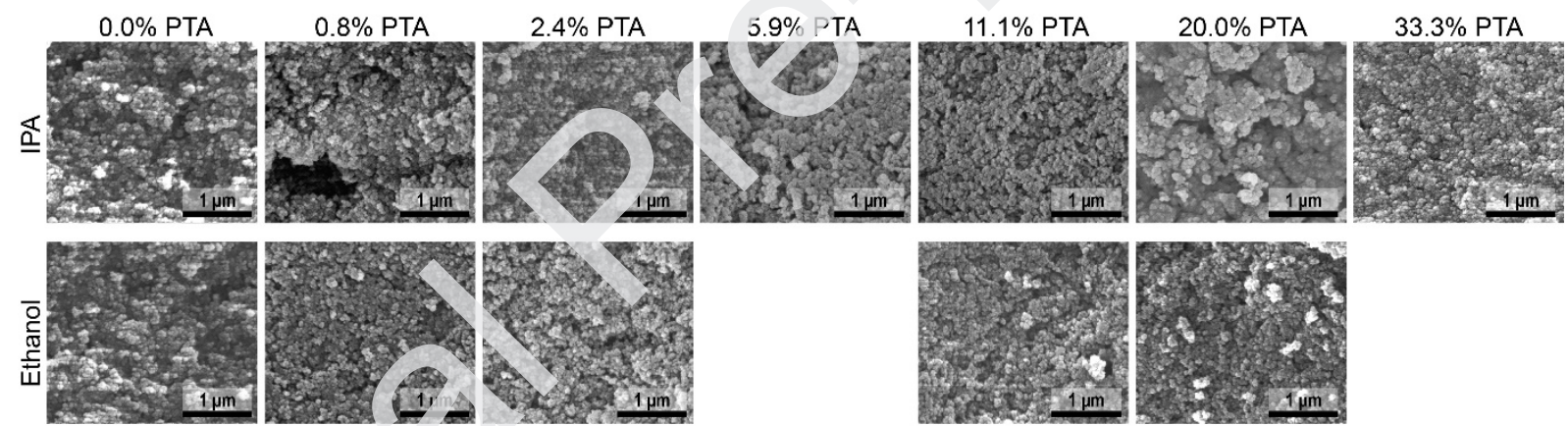

$10000 x$

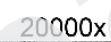

$50000 x$
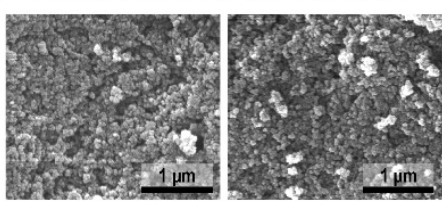

$200000 x$

$400000 x$
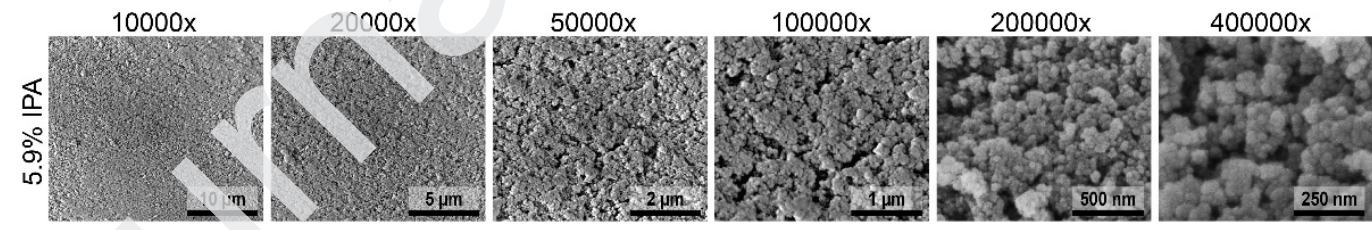

Figure 5. SEM images of silica aerogel powders prepared with variable amounts of isopropanol (top row) and ethanol (middle row) as PTA. SEM images of silica aerogel prepared with 5.9\% IPA at different magnifications. 


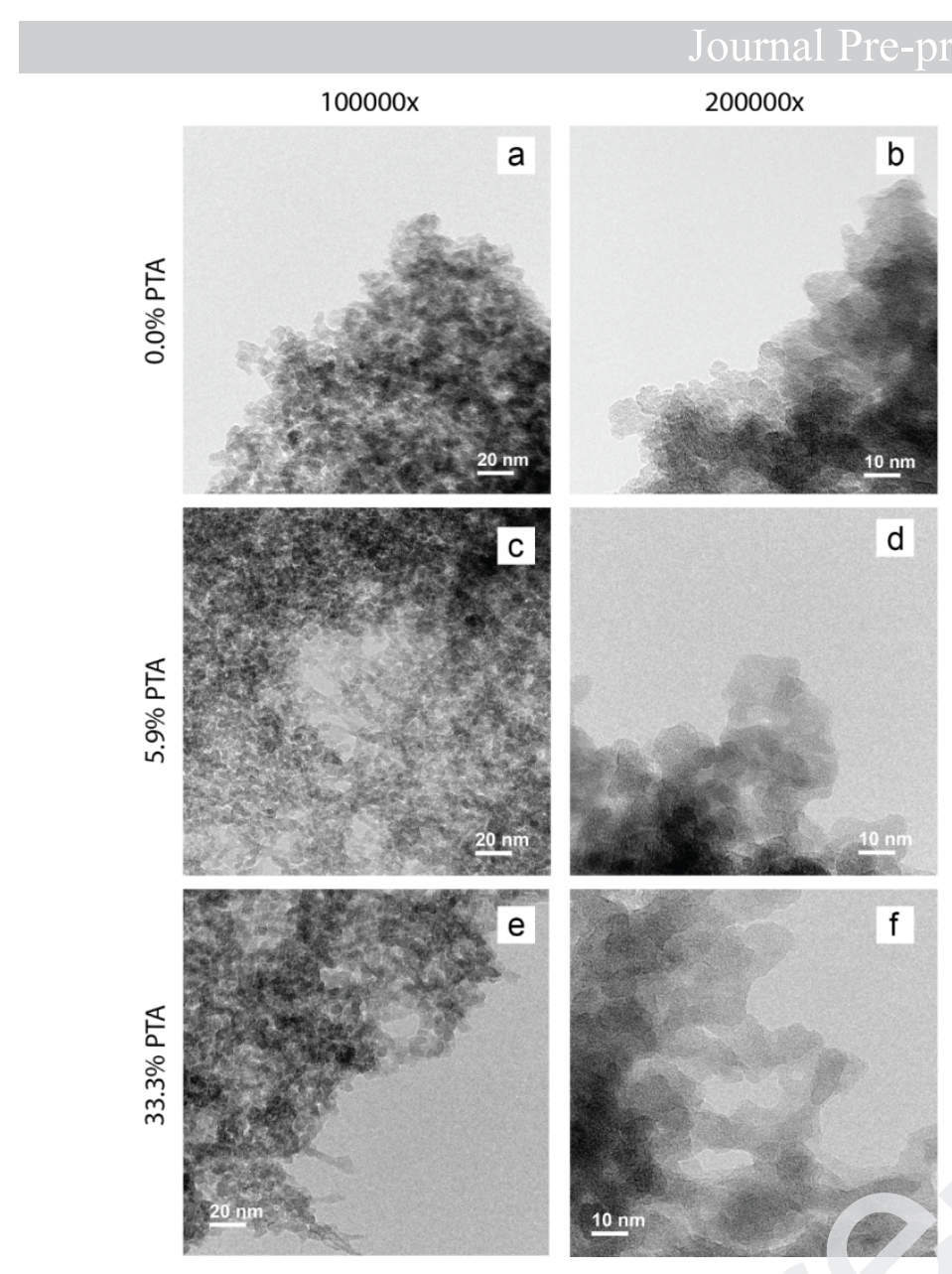

Figure 6. TEM images of silica aerogel powder prepared with (a-b) $0 \%$, (c-d) $5.9 \%$ and (e-f) $33.3 \%$ IPA.

The qualitative observations from the SEM images on the mesoporosity (Figure 5) are confirmed by the nitrogen sorption isotherms. All samples display the type IV isotherms expected for silica aerogels, with a relatively narrow hysteresis (Figure 7). The maximum adsorbed $N_{2}\left(\right.$ at $\left.P / P_{0}=0.998\right)$, which is a measure of the mesopore volume and a general indicator of aerogel quality, first increases and then decreases with increasing amounts of PTA added, qualitatively consistent with a higher (meso),porosity at intermediate contents of ethanol and isopropanol. The slopes of the isotherms at low partial pressure $\left(P / P_{0}<0.3\right)$, which are a measure of the specific surface area, increase with increasing contents of ethanol and isopropanol. 
The qualitative observations are confirmed by the BET and BJH analysis. The BET surface areas strongly increase upon the first addition of PTA (ethanol and isopropanol), followed by a slower increase (isopropanol) or plateau (ethanol) at higher concentrations (Figure 8a,d). Despite the complications arising from sample deformations during nitrogen sorption analysis [51], the BJH pore volume provides a measure of the mesopore volume. In both PTA series, a maximum in BJH pore volume (Figure $8 \mathrm{~b}, \mathrm{e}$ ) and average pore size (Figure $8 \mathrm{c}, \mathrm{f}$ ) is observed at intermediate contents of isopropanol and ethanol, consistent with the tap density minima for the same samples (Figure 4).

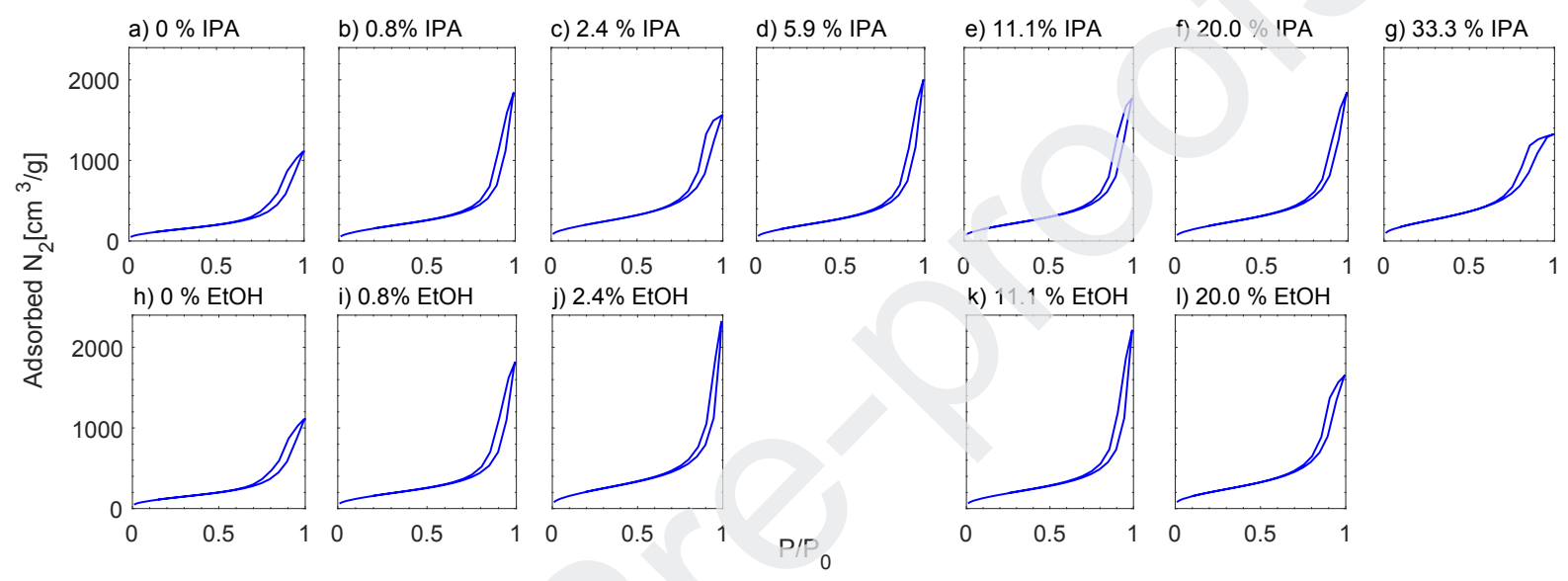

Figure 7. Nitrogen sorption isotherms for different quantities of isopropanol (a-g) and ethanol (h-l) used as PTA.

Note that a) and $h$ ) are from the same experiment (0\% PTA).
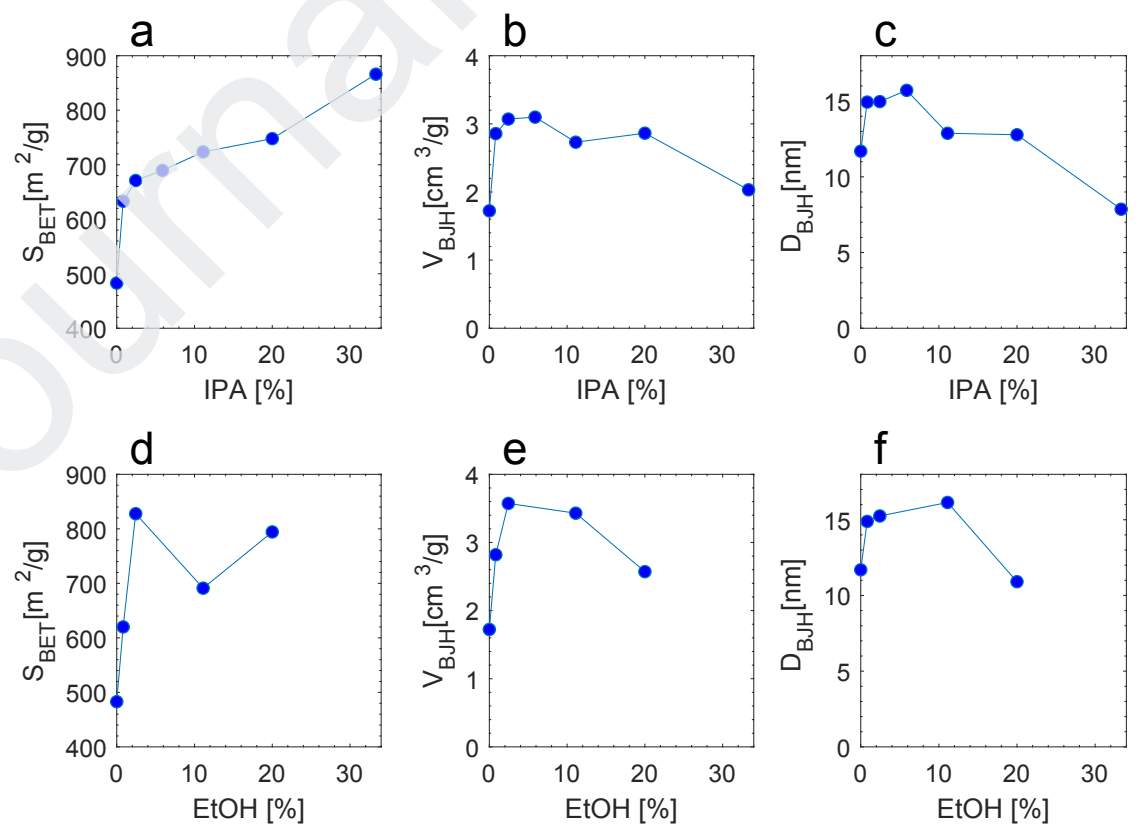
Figure 8. Surface area $\left(\mathrm{S}_{\mathrm{BET}}\right)$, mesopore volume $\left(\mathrm{V}_{\mathrm{BJH}}\right)$ and average pore size $\left(\mathrm{D}_{\mathrm{BJH}}\right)$ as a function of quantity of PTAs used, a-c) isopropanol, d-f) ethanol.

Powders prepared with low to intermediate, but non-zero amounts of PTAs are highly mesoporous with tap densities around or below $0.100 \mathrm{~cm}^{3} / \mathrm{g}$, high surface areas $\left(>700 \mathrm{~m}^{2} / \mathrm{g}\right)$ and relatively high BJH volume fractions $\left(>3 \mathrm{~cm}^{3} / \mathrm{g}\right)$. These values are typical for high-performance, superinsulating silica aerogels and the thermal conductivity of the aerogel phase is expected to be well below 20 $\mathrm{mW} /(\mathrm{m} \cdot \mathrm{K})$ based on these properties [1-4]. A direct measurement of the thermal conductivity of the aerogel phase itself is not possible, but the packed-bed thermal conductivity of the aerogel powder prepared with $11.1 \%$ of isopropanol was determined to be $19.4 \pm 1.0 \mathrm{~mW} /(\mathrm{m} \cdot \mathrm{K})$, i.e. close to that of a commercial silica aerogel powder with its thermal conductivity of $18.4 \pm 1.0 \mathrm{~mW} /(\mathrm{m} . \mathrm{K})$. Because the packed bed of aerogel powder consists of both aerogel and interstitial air pockets, the thermal conductivity of the aerogel phase itself ( $\lambda_{\text {aerogel }}$ ) must be lower. Based on the equation for thermal resistors in parallel $\lambda_{\text {powder }}=\mathrm{F} \cdot \lambda_{\text {aerogel }}+(1-\mathrm{F}) \cdot \lambda_{\text {air }}[53]$ and an estimated thermal conductivity of air $\left(\lambda_{\text {air }}\right)$ of $26 \mathrm{~mW} \mathrm{~m}^{-1} \mathrm{~K}^{-1}, \lambda_{\text {aerogel }}=\left(\lambda_{\text {powder }}-(1-F) \cdot 26\right) / F$, where $F$ is the filling factor or packing density, i.e. the volume fraction of aerogel in the powder bed. The packing density is not known a priori, since the envelope density of the aerogel grains themselves cannot be measured directly, but is expected to be between 0.80 (maximum packing density for polydisperse hard spheres [54]) and 0.55 (loose random packing for monodisperse spheres). These packing densities correspond to $\lambda_{\text {aerogel }}$ values between 14.0 and $17.8 \mathrm{nW} \mathrm{m}^{-1} \mathrm{~K}^{-1}$, respectively, i.e. values typical for high quality silica aerogel.

\section{Discussion}


All investigated properties paint a consistent picture of the effect of the PTA applied during synthesis, for both types of PTA. Best aerogel properties are reached for intermediate amounts of PTA. Compared to the reference system without PTA, the addition of a moderate amounts of isopropanol or ethanol (0.8-10 v\%) increases the hydrophobization efficiency (higher TMS content), decreases the density (i.e. shrinkage), increases the mesopore volume $\left(\mathrm{V}_{\mathrm{BJH}}\right)$, and increases the pore diameter $\left(D_{\text {вJH }}\right)$. At higher loadings of PTAs ( $\left.>\sim 10 \mathrm{ml}\right)$, the improved properties revert back towards those of the reference system. The surface area $\left(\mathrm{S}_{\mathrm{BET}}\right)$ data does not display such a pronounced maximum or minimum as a function of PTA content: a strong increase is observed upon the first few \% of addition, followed by a much slower increase or plateau at higher contents of PTA. Because incomplete hydrophobization leads to a strong and permanent densification during ambient pressure drying [47, $55,56]$, it is clear that at least some of the densification observed here is directly related to insufficient hydrophobization. Other factors, such as the mechanical properties and particle network structure may also depend on the amount of PTA added, and can also affect the final aerogel density. From the current dataset, the effect of PTA loading on the mechanical properties of the organogels cannot be determined, and it is therefore not clear to which extent the final aerogel density is affected by the mechanical properties of the gel.

In the following paragraph, we discuss the effect of the PTA on the hydrophobization process. The synthesis route involves multiple reactions and processes that are not well separated in time and space. Initially, dilute waterglass droplets are suspended in an organic, non-polar solvent (heptane) in the presence of the hydrophobization agent. The addition of the acid triggers the gelation of the waterglass droplets to form solid hydrogel particles. Simultaneously, the lower $\mathrm{pH}$ increases the hydrolysis rate of the hexamethyldisilazane [57] at the heptane/water interface (Figure 9). The resulting trimethylsilanol can then react with silanol groups of the silica hydrogel near the heptane/water interface, rendering the gel surface hydrophobic. Subsequently, the organic phase starts to infiltrate the gel pores with their newly hydrophobized surfaces, and displaces the aqueous phase (and its dissolved ionic guest spectators) from the pore network. As the TMS grafting reaction 
proceeds, the water/heptane interface progressively moves through the gel particles until the aqueous phase has been expelled and the particles are transferred from the aqueous to the organic phase. The key chemical reactions, i.e. the hydrolysis of hexamethyldisilazane and the grafting of TMS groups, both occur close to the solvent interface. The addition of the PTA decreases the incompatibility between heptane and water by weakening the barrier for diffusion of water into the organic phase, and perhaps most importantly, of trimethylsilanol into the aqueous phase. Hence, for small additions, it increases the interfacial contact area between the aqueous and organic phase and increases the kinetic rate of hydrophobization and phase transfer. This simple mociel helps explain why the addition of small to intermediate amounts of PTA increases the TMS content of the final aerogel, reduces shrinkage and density, and increases pore volume. We have shown that these beneficial effects disappear at high PTA loadings: both the aerogel quality and the degree of hydrophobization decrease as the system moves in the direction of a single-phase diffusive equilibration/dilution approach with a nearly miscible, three component solvent system (water, alcohol, heptane). The decrease in TMS content and deterioration of the aerogel properties at high PTA loadings may be related to the dilution of the organic phase and hydrophobization agent with the PTA, which reduces the activity and hence kinetic rate of the interfacial hydrophobization reaction. In addition, alcoholysis of silanol groups competes with silylation at high PTA loadings. In addition to these chemical effects, the PTA may also affect the mechanical properties of the gel. Because the PTA is added 30 minutes after the addition of the acid gelation catalyst, major effects on the gel structure are not expected, but the addition of an alcohol to the system may influence the silica solubility and thus the aging process, i.e. the dissolution-precipitation of silica at inter-particle necks, potentially leading to a weaker network structure and more pore collapse during ambient pressure drying [18]. 


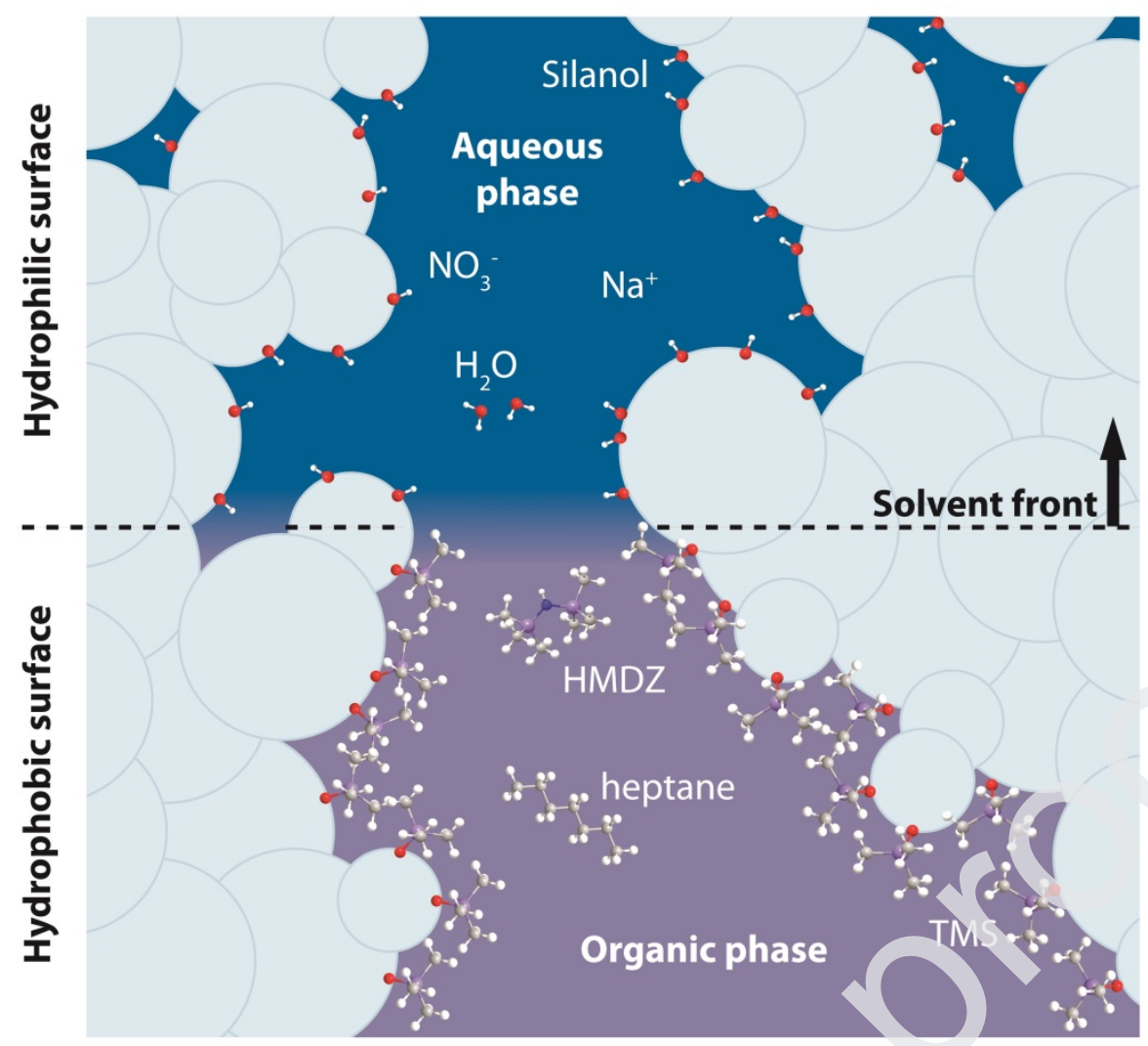

Figure 9. Schematic illustration of the single step hydrophobization and solvent/ion exchange process.

We now compare the current process to single-phase, TEOS based silica aerogel production in terms of raw materials cost and processing complexity, using our optimized TEOS based one-pot process as an example [26]. Compared to the TEOS process, the current process employs a less expensive silica precursor and the processing times are even shorter, thus there are clear advantages with respect to raw materials cost (by a factor of up to 2 ) and process duration. As with the TEOS based process, the organic solvent consumption ( $1.4 \mathrm{~m}^{3}$ of solvent per $\mathrm{m}^{3}$ of aerogel) approaches the theoretical minimum of $1 \mathrm{~m}^{3}$ solvent per $\mathrm{m}^{3}$ of aerogel, although the nature of the solvent and hydrophobe differ: heptane-HMDZ-isopropanol/ethanol here, versus ethanol-HMDSO for the TEOS process. One of the main drawbacks of the current process is its limitation to aerogel powders. The application of the current process to aerogel granulate or monoliths would require extensive adaptations and would most likely entail longer production times because of the difficulty and time required for the organic solvent to infiltrate larger hydrogel bodies/grains. 
In general, the materials produced with the described single step hydrophobization and solvent/ion exchange process, combined with a moderate amount of PTA, have excellent application-relevant properties. The ultra-low thermal conductivity and high mesoporosity make them attractive as a semi-finished product for applications in thermal insulation [2-4] or as a filler to reinforce polymer nanocomposites, e.g. with epoxy resins [58]. The synthesis procedure is a simple, one-pot process with great economic attractiveness. The silica precursor is non-ion-exchanged waterglass, arguably the least expensive silica source for aerogel production, and the relatively low aerogel densities further reduce the per-volume raw materials cost. The overall sol-gel process duration is less than two hours and less than three hours including APD, which makes continuous processing possible. The immiscibility of the two main solvents, water and heptane, allows for a simple and cost-effective separation by means of decantation. Side products $\left(\mathrm{Na}^{+}, \mathrm{NH}_{4}{ }^{+}, \mathrm{NO}_{3}{ }^{-}\right)$are easily removed from the system with the aqueous phase. Thus, this method of silica aerogel powder production represents a competitive way to reduce both the raw materiais and processing cost of silica aerogel.

\section{Conclusions}

Our data on silica aerogel powders prepared from non-ion-exchanged waterglass (sodium silicate) and a hydrophobization agent in an immiscible organic solvent (hexamethyldisilazane in heptane) demonstrate that the use of appropriate amounts of PTA strongly improves the application relevant properties of silica aerogel powders. Low to intermediate amounts (1-10\%) of ethanol or isopropanol added during the synthesis increase the hydrophobization efficiency and decrease the shrinkage during ambient pressure drying, with slightly better properties observed for the ethanol based PTA system. The resulting silica aerogel powders display high surface areas, high mesopore volumes, low tap densities and a very low thermal conductivity. The simplicity and speed of the synthesis process, combined with the use of an inexpensive silica precursor, can enable a much needed reduction of the production cost of high quality silica aerogel materials. 


\section{Author contributions}

S.Z., A.S., M.M.K. and W.J.M. designed the study. E.A., O.E., S.Z. and A.S. optimized and carried out the synthesis. S.Z. performed the SEM, BET and tap density measurements. W.J.M. and D.R. conducted the NMR analysis and interpretation. R.P. and S.Z. conducted the TEM measurements. W.J.M. wrote the first draft of the manuscript with input from all co-authors.

\section{Notes}

Empa owns equity in a filed patent related to the use of a PTA for silica aerogel production.

\section{Acknowledgment}

We thank Samuel Brunner for his input and assistance with the thermal conductivity measurements, the Concrete \& Construction Chemistry Laboratory at Empa for access to the tap density and particle size distribution measurement devices and the Cellulose \& Wood Materials Laboratory at Empa for access to the water contact angie measurement setup. The NMR spectrometer was funded in part by grant 150638 from the Swiss National Science Foundation.

\section{References}

[1] M.A. Aegerter, N. Leventis, M.M. Koebel, Aerogels handbook, Springer, New York, 2011.

[2] M. Koebel, A. Rigacci, P. Achard, Aerogel-based thermal superinsulation: an overview, J. Sol-Gel Sci. Technol. 63 (2012) 315-339.

[3] R. Baetens, B.P. Jelle, A. Gustavsen, Aerogel insulation for building applications: A state-of-the-art review, Energy and Buildings 43 (2011) 761-769.

[4] M.M. Koebel, J. Wernery, W.J. Malfait, Energy in buildings-Policy, materials and solutions, MRS Energy \& Sustainability 4 (2017) E12.

[5] H. Maleki, L. Duraes, A. Portugal, An overview on silica aerogels synthesis and different mechanical reinforcing strategies, J. Non-Cryst. Solids 385 (2014) 55-74.

[6] G. Zhang, A. Dass, A.-M.M. Rawashdeh, J. Thomas, J.A. Counsil, C. Sotiriou-Leventis, E.F. Fabrizio, F. Ilhan, P. Vassilaras, D.A. Scheiman, L. McCorkle, A. Palczer, J.C. Johnston, M.A. Meador, N. 
Leventis, Isocyanate-crosslinked silica aerogel monoliths: preparation and characterization, J. Non-Cryst. Solids 350 (2004) 152-164.

[7] A. Katti, N. Shimpi, S. Roy, H. Lu, E.F. Fabrizio, A. Dass, L.A. Capadona, N. Leventis, Chemical, Physical, and Mechanical Characterization of Isocyanate Cross-linked Amine-Modified Silica Aerogels, Chem. Mater. 18 (2005) 285-296.

[8] G. Churu, B. Zupančič, D. Mohite, C. Wisner, H. Luo, I. Emri, C. Sotiriou-Leventis, N. Leventis, H. Lu, Synthesis and mechanical characterization of mechanically strong, polyurea-crosslinked, ordered mesoporous silica aerogels, J. Sol-Gel Sci. Technol. 75 (2015) 98-123.

[9] L.A. Capadona, M.A.B. Meador, A. Alunni, E.F. Fabrizio, P. Vassilaras, N. Leventis, Flexible, lowdensity polymer crosslinked silica aerogels, Polymer 47 (2006) 5754-5761.

[10] S.L. Vivod, M.A.B. Meador, B.N. Nguyen, R. Perry, Flexible di-isocyanate cross-linked silica aerogels with 1, 6-bis (trimethoxysilyl) hexane incorporated in the underlying silica backbone, Polym Preprints 50 (2009) 119-120.

[11] S. Zhao, W.J. Malfait, A. Demilecamps, Y. Zhang, S. Brunner, L. Huber, P. Tingaut, A. Rigacci, T. Budtova, M.M. Koebel, Strong, Thermally Superinsulating Biopolymer-Silica Aerogel Hybrids by Cogelation of Silicic Acid with Pectin, Angew. Chem. Int. Ed. 54 (2015) 14282-14286.

[12] S. Zhao, Z. Zhang, G. Sèbe, R. Wu, R.V. Rivera Virtudazo, P. Tingaut, M.M. Koebel, Multiscale Assembly of Superinsulating Silica Aerogels Within Silylated Nanoceliulosic Scaffolds: Improved Mechanical Properties Promoted by Nanoscale Chemical Compatibilization, Adv. Funct. Mater. 25 (2015) 2326-2334.

[13] S. Zhao, W.J. Malfait, E. Jeong, B. Fischer, Y. Zhang, H. Xu, E. Angelica, W.M. Risen, J.W. Suggs, M.M. Koebel, Facile One-Pot Synthesis of Mechanically Robust Biopolymer-Silica Nanocomposite Aerogel by Cogelation of Silicic Acid with Chitosan in Aqueous Media, ACS Sustainable Chem. Eng. 4 (2016) 5674-5683.

[14] S. Zhao, O. Emery, A. Wohlhauser, M.M. Koebel, C. Adlhart, W.J. Malfait, Merging flexibility with superinsulation: Machinable, nanofibrous pullulan-silica aerogel composites, Materials \& Design 160 (2018) 294-302.

[15] S. Iswar, G.M. Snellings, S. Zhao, R. Erni, Y.K. Bahk, J. Wang, M. Lattuada, M.M. Koebel, W.J. Malfait, Reinforced and superinsulating silica aerogel through in situ cross-linking with silane terminated prepolymers, Acta Mater. 147 (2018) 322-328.

[16] G. Zu, K. Kanamori, A. Maeno, H. Kaji, K. Nakanishi, Superflexible Multifunctional Polyvinylpolydimethylsiloxane-Based Aerogels as Efficient Absorbents, Thermal Superinsulators, and Strain Sensors, Angew. Chem. Int. Ed. 57 (2018) 9722-9727.

[17] S.S. Prakash, J.C. Brinker, A.J. Hurd, S.M. Rao, Silica aerogel films prepared at ambient pressure by using surface derivatization to induce reversible drying shrinkage, Nature 375 (1995) 431431.

[18] S. Iswar, W.J. Nialfait, S. Balog, F. Winnefeld, M. Lattuada, M.M. Koebel, Effect of aging on silica aeroge' properties, Microporous Mesoporous Mater. 241 (2017) 293-302.

[19] F. Schwertfeger, D. Frank, M. Schmidt, Hydrophobic waterglass based aerogels without solvent exchange or supercritical drying, J. Non-Cryst. Solids 225 (1998) 24-29.

[20] P.M. Shewale, A.V. Rao, A.P. Rao, Effect of different trimethyl silylating agents on the hydrophobic and physical properties of silica aerogels, Appl. Surf. Sci. 254 (2008) 6902-6907.

[21] H.-Y. Nah, V.G. Parale, K.-Y. Lee, C.-H. Lim, Y.S. Ku, H.-H. Park, Role of oxalic acid in structural formation of sodium silicate-based silica aerogel by ambient pressure drying, J. Sol-Gel Sci. Technol. 85 (2018) 302-310.

[22] S. Yun, H. Luo, Y. Gao, Superhydrophobic silica aerogel microspheres from methyltrimethoxysilane: rapid synthesis via ambient pressure drying and excellent absorption properties, RSC Adv. 4 (2014) 4535-4542.

[23] J.C.H. Wong, H. Kaymak, S. Brunner, M.M. Koebel, Mechanical properties of monolithic silica aerogels made from polyethoxydisiloxanes, Microporous Mesoporous Mater. 183 (2014) 23-29. 
[24] T.S. Rani, M. Subha, G. Venkata Reddy, Y.H. Kim, Y.S. Ahn, Synthesis of water-glass-based silica aerogel powder via with and without squeezing of hydrogels, J. Appl. Polym. Sci. 115 (2010) 1675-1679.

[25] M.S. Gilani, S. Zhao, S. Gaan, M. Koebel, T. Zimmermann, Design of a hierarchically structured hybrid material via in situ assembly of a silica aerogel into a wood cellular structure, RSC Adv. 6 (2016) 62825-62832.

[26] L. Huber, S. Zhao, W.J. Malfait, S. Vares, M.M. Koebel, Fast and Minimal-Solvent Production of Superinsulating Silica Aerogel Granulate, Angew. Chem. Int. Ed. 56 (2017) 4753-4756.

[27] D. Jantke, K. Hindelang, R. Weidner, Economically viable process for producing organically modified lyo-or aerogels, US Patents US20180105429, 2018.

[28] A.V. Rao, M.M. Kulkarni, D. Amalnerkar, T. Seth, Superhydrophobic silica aerogels based on methyltrimethoxysilane precursor, J. Non-Cryst. Solids 330 (2003) 187-195.

[29] D.Y. Nadargi, A.V. Rao, Methyltriethoxysilane: New precursor for synthesizing silica aerogels, J. Alloys Compd. 467 (2009) 397-404.

[30] A. Venkateswara Rao, S.D. Bhagat, H. Hirashima, G.M. Pajonk, Synthesis of flexible silica aerogels using methyltrimethoxysilane (MTMS) precursor, J. Colloid Interface Sci. 300 (2006) 279-285.

[31] L. Durães, A. Maia, A. Portugal, Effect of additives on the properties of silica based aerogels synthesized from methyltrimethoxysilane (MTMS), J. Supercrit. Fluids 106 (2015) 85-92.

[32] W. Zhang, Z. Li, L. Shi, Z. Li, Y. Luo, Q. Liu, R. Huang, Methyltrichlorosilane modified hydrophobic silica aerogels and their kinetic and thermodynamic behaviors, J. Sol-Gel Sci. Technol. (2018) 110.

[33] M.M. Koebel, L. Huber, S. Zhao, W.J. Malfait, Breakthroughs in cost-effective, scalable production of superinsulating, ambient-dried silica aerogel and silica-biopolymer hybrid aerogels: from laboratory to pilot scale, J. Sol-Gel Sci. Technol. 79 (2016) 308-318.

[34] L.J. Wang, S.Y. Zhao, M. Yang, Structural characteristics and thermal conductivity of ambient pressure dried silica aerogels with one-step solvent exchange/surface modification, Mater. Chem. Phys. 113 (2009) 485-490

[35] C.J. Lee, G.S. Kim, S.H. Hyun, Synthesis of silica aerogels from waterglass via new modified ambient drying, J. Mater. Sci. 37 (2002) 2237-2241.

[36] S.-W. Hwang, H.-H. Jung, S.-H. Hyun, Y.-S. Ahn, Effective preparation of crack-free silica aerogels via ambient drying, J. Sol-Gel Sci. Technol. 41 (2007) 139-146.

[37] F. Shi, L. Wang, J. Liu, Synthesis and characterization of silica aerogels by a novel fast ambient pressure drying process, Mater. Lett. 60 (2006) 3718-3722.

[38] S.D. Bhagat, Y.H. Kim, Y.S. Ahn, J.G. Yeo, Rapid synthesis of water-glass based aerogels by in situ surface modification of the hydrogels, Appl. Surf. Sci. 253 (2007) 3231-3236.

[39] Y. Pan, S. He, X. Cheng, Z. Li, C. Li, Y. Huang, L. Gong, A fast synthesis of silica aerogel powdersbased on water glass via ambient drying, J. Sol-Gel Sci. Technol. 82 (2017) 594-601.

[40] S.-W. Hwang, T.-Y. Kim, S.-H. Hyun, Optimization of instantaneous solvent exchange/surface modification process for ambient synthesis of monolithic silica aerogels, J. Colloid Interface Sci. 322 (2008) 224-230.

[41] J. Chul Young, R. Je Myung, Y. Jong Young, P. Chul Jong, C. Hee Jung, K. Min Woo Method of preparing silica aerogel powder US patents, US20120225003A1, 2011.

[42] S. De Pooter, S. Latré, F. Desplentere, D. Seveno, Optimized synthesis of ambient pressure dried thermal insulating silica aerogel powder from non-ion exchanged water glass, J. Non-Cryst. Solids 499 (2018) 217-226.

[43] K.J. Lee, Y.H. Kim, J.K. Lee, H.J. Hwang, Fast Synthesis of Spherical Silica Aerogel Powders by Emulsion Polymerization from Water Glass, ChemistrySelect 3 (2018) 1257-1261.

[44] M. Firoozmandan, J. Moghaddas, N. Yasrebi, Performance of water glass-based silica aerogel for adsorption of phenol from aqueous solution, J. Sol-Gel Sci. Technol. 79 (2016) 67-75.

[45] M. de Fátima Júlio, L.M. Ilharco, Superhydrophobic hybrid aerogel powders from waterglass with distinctive applications, Microporous Mesoporous Mater. 199 (2014) 29-39. 
[46] A. Stojanovic, S. Zhao, E. Angelica, W.J. Malfait, M.M. Koebel, Three routes to superinsulating silica aerogel powder, J. Sol-Gel Sci. Technol. 90 (2019) 57-66.

[47] W.J. Malfait, R. Verel, M.M. Koebel, Hydrophobization of Silica Aerogels: Insights from Quantitative Solid-State NMR Spectroscopy, J. Phys. Chem. C 118 (2014) 25545-25554.

[48] W.J. Malfait, S. Zhao, R. Verel, S. Iswar, D. Rentsch, R. Fener, Y. Zhang, B. Milow, M.M. Koebel, Surface Chemistry of Hydrophobic Silica Aerogels, Chem. Mater. 27 (2015) 6737-6745.

[49] S. Brunauer, P.H. Emmett, E. Teller, Adsorption of Gases in Multimolecular Layers, J. Am. Chem. Soc. 60 (1938) 309-319.

[50] E.P. Barrett, L.G. Joyner, P.P. Halenda, The Determination of Pore Volume and Area Distributions in Porous Substances. I. Computations from Nitrogen Isotherms, J. Am. Chem. Soc. 73 (1951) 373-380.

[51] G. Reichenauer, Structural Characterization of Aerogels, in: M.A. Aegerter, N. Leventis, M.M. Koebel (Eds.) Aerogels Handbook, Springer New York2011, pp. 449-498.

[52] T. Stahl, S. Brunner, M. Zimmermann, K. Ghazi Wakili, Thermo-hygric properties of a newly developed aerogel based insulation rendering for both exterior and interior applications, Energy and Buildings 44 (2012) 114-117.

[53] S. Iswar, M. Griffa, R. Kaufmann, M. Beltran, L. Huber, S. Brunner, M. Lattuada, M.M. Koebel, W.J. Malfait, Effect of aging on thermal conductivity of fiber-reinforced aerogel composites: An X-ray tomography study, Microporous Mesoporous Mater. 278 (2019) 289-296.

[54] G.J. lafrate, J.F. Ziegler, M.J. Nass, Application of Lindhard's dielectric theory to the stopping of ions in solids, J. Appl. Phys. 51 (1980) 984-987.

[55] W. Li-Jiu, Z. Shan-Yu, Y. Mei, Structural characteristics and thermal conductivity of ambient pressure dried silica aerogels with one-step solvent exchange/surface modification, Mater. Chem. Phys. 113 (2009) 485-490.

[56] C. Yamagata, D.R. Elias, M.R.S. Paiva, A.M. Misso, S. Castanho, Influence of the precursor concentration on the characteristics of silica powder obtained from $\mathrm{Na2SiO3}$ by a facile lowtemperature synthesis process, Journal of Materials Science and Engineering B 2 (2012) 429436.

[57] L. Yi-bing, Analysis of the Hydrolyzate of Trimethylchlorosilane and Hexamethyldisilazane, Environmental Monitoring in China 1 (2012) 016.

[58] S. Salimian, A. Zadhoush, Z. Talebi, B. Fischer, P. Winiger, F. Winnefeld, S. Zhao, M. Barbezat, M.M. Koebel, W.J. Maifait, Silica Aerogel-Epoxy Nanocomposites: Understanding Epoxy Reinforcement in Terms of Aerogel Surface Chemistry and Epoxy-Silica Interface Compatibility, ACS Applied Nano Materiais 1 (2018) 4179-4189. 


\section{Highlights}

- Simple aerogel synthesis from low-cost silica precursor without ion exchange

- Superinsulating silica aerogel powder produced in less than three hours

- Phase transfer agent improves hydrophobization and application relevant properties

- Silica aerogel powder displays high surface area and mesopore volume 